Int. J. Curr. Res. Med. Sci. (2017). 3(8): 65-70

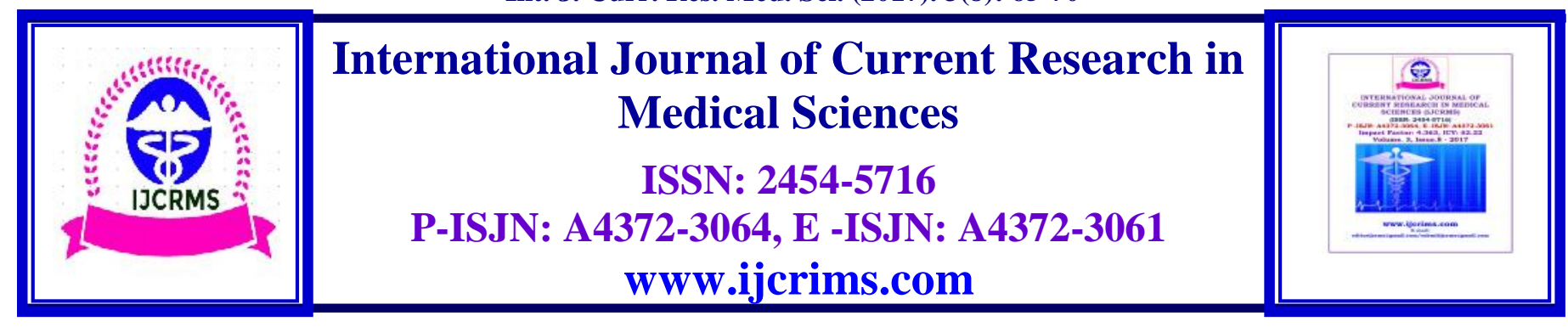

Original Research Article

Volume 3, Issue 8 -2017

DOI: http://dx.doi.org/10.22192/ijcrms.2017.03.08.011

\title{
A Study of the relation of BMI with dysmenorrhea in adolescents girls
}

\author{
*Gurdip Kaur, **Parmjit Kaur, ***Himani \\ *Associate Professor, **Professor, ***Junior Resident, Department of Obstetrics \& Gynaecology, \\ Govt. Medical College/Rajindra Hospital, Patiala, 147001, Punjab, India \\ Corresponding Author: Dr. Gurdip Kaur, Associate Professor, Dept. of Obstetrics \& Gynaecology, \\ Govt. Medical College/Rajindra Hospital, Patiala, 147001, India \\ E-mail:drgurdipkaur@gmail.com
}

\begin{abstract}
Introduction: Adolescence is the segment of life between 10-19 years of age. Dysmenorrhea refers to a cyclical lower abdominal or pelvic pain occurring during menstruation which may radiate to the back or to the thighs. It is necessary to clarify what factors are associated with menstrual pain in adolescence, to assist in improving quality of life. The present study was conducted to see the relation of BMI with dysmenorrhea.

Aims \&Objectives: To record the Body Mass Index (BMI) of the adolescents and statistically evaluate the relation of the BMI with dysmenorrhea in adolescent girls.

Materials and methods: It was a prospective study which was conducted on 450 adolescent girls (between 10-19 years) from January 2015 to June 2016 attending selected senior secondary schools and gynaecological outdoor of Government Medical College and Rajindra Hospital Patiala with complaint of dysmenorrhea. All participants were given a predesigned questionnaire to complete. All eligible participants were subjected to anthropometric measurements and BMI was calculated according to WHO criteria. The relation between BMI and severity of dysmenorrhea was analysed. Intensity of pain was assessed by multidimensional scoring system of Andersch and Milson(MSS scoring 0, 1, 2, and 3)

Results: A total of 450 students were studied .The average age of study group was $15.51+/-1.27$ years and average BMI of the complete study group was found to be $18.81+/-3.36 \mathrm{~kg} / \mathrm{m}^{2}$. A statistical significant relation was found between low BMI and high BMI with severe dysmenorrhea $(\mathrm{P}<0.0028)$. A highly significant relation was also found between severity of dysmenorrhea and psychological symptoms $(\mathrm{P}<0.0000)$

Conclusion: We concluded that severity of dysmenorrhoea has significant relation with BMI (underweight and overweight) and psychological symptoms in adolescent girls.
\end{abstract}

Keywords: adolescence, dysmenorrhoea, BMI 


\section{Introduction}

WHO defines adolescence as the segment of life between 10-19 years of age. ${ }^{1}$ The adolescent girls are very shy persons and often hesitate to seek help regarding their problems. Social customs and taboos regarding mensuration hamper the efforts in establishing early diagnosis of their disorders. ${ }^{2}$ Problems with menstrual pattern may affect $75 \%$ girls and are the major cause of recurrent short term school absenteeism in female students. Menstrual problems are generally perceived as minor health problems and thus irrelevant to public health agenda particularly for females in developing countries who may face life threatening complications. ${ }^{3}$ Dysmenorrhoea refers to a cyclical lower abdominal pain or pelvic pain occurring during menstruation which may radiate to the back or to the thighs. ${ }^{4}$ Adysmenorrheic mother usually has a dysmenorrheic daughter. A girl who is an only child is more likely than most to suffer from dysmenorrhea. It is often very difficult to separate the respective contributions of physiological and psychological factors and such factors may make dysmenorrhea worse even if they do not cause it. ${ }^{5}$ Some studies establish positive relation between dysmenorrhea in adolescent and low BMI. Hence, improvement of their BMI by ensuring intake of a healthy and balanced diet may go a long way in relieving young adolescent girls of dysmenorrhea and enable them to mature into socially and economically productive members of society.

\section{Aims \& Objectives}

To record the Body Mass Index (BMI) of the adolescents and statistically evaluate the relation of the BMI with dysmenorrhoea in adolescent girls.

\section{Materials and Methods}

It was a prospective study which was conducted on 450 adolescent girls (between 10-19 years) from January 2015 to June 2016 attending selected senior secondary schools and gynaecological outdoor of Government Medical College and Rajindra Hospital Patiala with complaint of dysmenorrhea. Adolescent with physical illness, any history of mental illness, taking any kind of psychotropic drugs or refusal to participate in the study were excluded. All participants were given a predesigned questionnaire to complete and then they were subjected to anthropometric measurements such as weight (in kilograms) and height (in meters)and BMI was calculated. Nutritional status of the subject was calculated as normal, overweight and under nourished as per WHO criteria. ${ }^{6}$ The relation between BMI and severity of dysmenorrhea was analysed. Intensity of pain was assessed by multidimensional scoring system of Andersch and Milson (MSS scoring 0,1,2, and $3)^{7}$

Grade 0 - No pain

Grade 1-Mild

Grade 2-Moderate

Grade 3 -Severe

The data was compiled and analysed statistically by calculating mean, standard deviation and chi square test for statistical significance. Relation of BMI with dysmenorrhea was calculated.

\section{Observations}

There were 450 adolescent girls in the present study. Majority of them belonged to 14-16 years (75.78\%) age group and mean age came out to be $15.51 \pm 1.27$ years. (Table No 1)

Table No 1: Age distribution of adolescents

\begin{tabular}{|l|c|c|}
\hline Age Group ( years) & Number of girls & Percentage \\
\hline $10-13$ & 20 & 4.44 \\
\hline $14-16$ & 341 & 75.78 \\
\hline $17-19$ & 89 & 18.78 \\
\hline Mean age & 450 & $15.51 \pm 1.27$ years \\
\hline Total & \multicolumn{2}{|c|}{100} \\
\hline
\end{tabular}


Int. J. Curr. Res. Med. Sci. (2017). 3(8): 65-70

Majority of adolescents (58.89\%) had mild dysmenorrhoea in the present study followed by moderate dysmenorrhoea in $34.44 \%$ and severe dysmenorrhoea in6.67\%. (Table No 2)

Table No 2: Distribution of girls as per severity of dysmenorrheal

\begin{tabular}{|l|c|c|}
\hline \multicolumn{1}{|c|}{ Severity of dysmenorrhoea } & No of girls & Percentage \\
\hline Mild(MSS score-1) & 265 & 58.89 \\
\hline Moderate(MSS score-2) & 155 & 34.44 \\
\hline Severe(MSS score-3) & 30 & 6.67 \\
\hline Total & 450 & 100 \\
\hline
\end{tabular}

Table No 3: Distribution of Adolescent girls as per WHO classification of BMI

\begin{tabular}{|l|c|c|c|}
\hline \multicolumn{1}{|c|}{ Category } & BMI $\left(\mathbf{k g} / \mathbf{m}^{\mathbf{2}}\right)$ & No. of participants & Percentage \\
\hline Underweight & $<18.5$ & 245 & 54.54 \\
\hline Normal range & $18.5-24.99$ & 181 & 40.22 \\
\hline Pre-obese & $25-29.99$ & 19 & 4.22 \\
\hline Obese class-I & $30-34.99$ & 5 & 1.11 \\
\hline Total & & 450 & 100 \\
\hline
\end{tabular}

Most of the adolescents (54.54\%)had BMI less than $18.5 \mathrm{~kg} / \mathrm{m}^{2}$ and were underweight. Nearly
181(40.22\%) had normal BMI. $24(5.33 \%)$ had high BMI. (Table No 3)

Table No 4: Relation of BMI and severity of dysmenorrhea in Adolescent girls

\begin{tabular}{|c|c|c|c|c|c|c|c|c|c|}
\hline \multirow{2}{*}{ Category } & \multirow{2}{*}{$\operatorname{BMI}\left(\mathrm{kg} / \mathrm{m}^{2}\right)$} & \multicolumn{2}{|c|}{ MSS 1} & \multicolumn{2}{|c|}{ MSS 2} & \multicolumn{2}{|c|}{ MSS 3} & \multicolumn{2}{|c|}{ Total } \\
\hline & & No. & \%age & No. & \%age & No. & $\%$ age & No. & \%age \\
\hline Underweight & $<18.5$ & 132 & 53.88 & 95 & 38.76 & 18 & 7.36 & 245 & 100 \\
\hline Normal range & $18.5-24.99$ & 120 & 66.30 & 54 & 29.83 & 7 & 3.87 & 181 & 100 \\
\hline Pre-obese & $25-29.99$ & 10 & 52.63 & 4 & 21.10 & 5 & 26.32 & 19 & 100 \\
\hline Obese class-I & $30-34.99$ & 3 & 60 & 2 & 40 & 0 & --- & 5 & 100 \\
\hline \multicolumn{2}{|c|}{ Chi square value } & \multicolumn{4}{|c|}{ Df } & \multicolumn{4}{|c|}{ Significance } \\
\hline \multicolumn{2}{|c|}{19.979} & \multicolumn{4}{|c|}{6} & \multicolumn{4}{|c|}{.0028} \\
\hline
\end{tabular}

In the underweight population, majority 132 (53.88\%) had mild dysmenorrhea, 95 (38.76\%) moderate dysmenorrhea and 18 (7.36\%) had severe dysmenorrhea. In overweight girls, $26.32 \%$ had severe dysmenorrhea.

There is a statistically significant relation between the severity of dysmenorrhea and BMI in our study group. In adolescent girls with normal BMI, only $3.87 \%$ had severe dysmenorrhea as compared to $7.36 \%$ in underweight and $26.32 \%$ in overweight adolescents. Hence a positive relation between low BMI and high BMI (underweight and overweight) with severity of dysmenorrhea was inferred. (Table No 4) 
Int. J. Curr. Res. Med. Sci. (2017). 3(8): 65-70

Table No 5: Relation of psychological symptoms with severity of dysmenorrhoea

\begin{tabular}{|c|c|c|c|}
\hline \multirow[b]{2}{*}{ MSS Score } & \multicolumn{2}{|c|}{ Psychological Symptoms } & \multirow{2}{*}{$\begin{array}{l}\text { \%age of Adolescents with } \\
\text { psychological symptoms }\end{array}$} \\
\hline & No & Yes & \\
\hline 1 & 166 & 99 & 37.36 \\
\hline 2 & 40 & 115 & 74.19 \\
\hline \multirow[t]{2}{*}{3} & 3 & 27 & 90.00 \\
\hline & 209 & 241 & 53.56 \\
\hline Chi square value & \multicolumn{2}{|c|}{ Df } & Significance \\
\hline 70.511 & \multicolumn{2}{|c|}{2} & 0.0000 \\
\hline
\end{tabular}

A large number of adolescents $(53.56 \%)$ in the study group had psychological symptoms associated with mensuration. Among these, majority (90\%) of adolescents with severe dysmenorrhea (MSS score 3) experienced psychological symptoms where as only $37.36 \%$ of adolescent girls with mild dysmenorrheal (MSS score-1) has such complaints.

On statistical analysis, the relation between severity of dysmenorrhea and psychological symptoms was shown to be highly significant. (Table No 5) As the severity of dysmenorrhea increased, the prevalence of psychological symptoms also increased significantly. Hence there was a positive relation between psychological symptoms and severity of dysmenorrhea.

\section{Discussion}

Adolescent gynaecology is an emerging speciality. Problems with menstrual pattern affect $75 \%$ girls and are the major cause of recurrent short term school absenteeism in female students. High prevalence of malnutrition among adolescent results showed increased reproductive problems in young women. ${ }^{8}$ Majority of adolescent girls $(75.78 \%)$ in present study were in the age group of 14-16 Years. The mean age of the study group was $15.51 \pm 1.2$ years which is comparable to study of Khodakarami B et al $(2015)^{9}$ who also reported a mean age of $15.94 \pm 1.17$ years. The mean BMI of the complete study group was $18.81+/-3.36 \mathrm{Kg} / \mathrm{m}^{2}$. Majority of adolescents had low BMI (54.44\%) followed by normal BMI in $40.22 \%$ and $5.33 \%$ had high BMI which is comparable to study done by Patil
SN et al (2009) ${ }^{10}$ but differs from study by Abdella NHA (2016) ${ }^{11}$ et al who found $53.8 \%$ adolescents with normal weight, while $33.9 \%$, $12.0 \%$ were overweight \& obese respectively. Maximum (58.89 \%) adolescents in our study had mild dysmenorrhoea followed by moderate dysmenorrhea (34.44 \%) and severe dysmenorrhea $(6.67 \%)$ which is comparable to study of Chauhan et al (2012) ${ }^{4}$ and El-Glany et al (2005). ${ }^{12}$ In our study there was a statistically significant relation between severity of dysmenorrhea and abnormal BMI $\left(<18.5 \mathrm{Kg} / \mathrm{m}^{2}\right.$ and $>24.99 \mathrm{Kg} / \mathrm{m}^{2)}$. But association was more significant for high BMI as compared to underweight population. These results are in accordance with those of Chauhan et al $(2012)^{4}$, RupaVani et al $(2013)^{13}$ and Hong $\mathrm{Ju}$ et al $(2015)^{14}$ but differ from Khodakarami B et al $(2015)^{9}$ who found the frequency and severity of dysmenorrhea to be higher in the normal-weight group than other subjects whereas Margaret and Dash $(2016)^{15}$ in their study could not elicit any association of BMI with dysmenorrhoea Our study demonstrated a statistically highly significant relation of severity of dysmenorrhea with prevalence of psychological symptoms. It is comparable with Lee LK et al (2006) ${ }^{16}$, T Santina et al (2012) ${ }^{17}$ and Suresh K. Khumbhar et al (2011). ${ }^{18}$ None of the studies have shown severity of dysmenorrhea with high BMI. This can be due to less number of adolescents with high BMI in our study group (24 out of $450 ; 5.33 \%$ ). A statistically significant relationship was found between BMI and severity of premenstrual symptoms including psychological symptoms (anxiety- depression-nervous) by Abdella NHA et al $(2016)^{11}$. 


\section{Conclusion}

Healthy adolescent girls of today are tomorrow's healthy women, future of every society and great resource of the nation. We should aim to improve their quality of life and for that, it is imperative that due importance is to be given to the needs of girls in this crucial period of life. There should be more collaboration and networking at all levels of health systems to provide better information on reproductive health. There is statistically significant relation between low BMI and high BMI with the severity of dysmenorrhoea. Our study demonstrated statistically high significant relation of severity of dysmenorrhea with prevalence of psychological symptoms.

\section{Source of funding: Nil}

\section{Conflict of interest: None declared}

\section{References}

1. Kulkarni MV and Durge PM. Reproductive Health Morbidities among Adolescent Girls: Breaking the Silence. Ethno Med 2011; 5(3): 165-8.

2. Bhayani BS, Singhal A, Tripathi KG, Saraiya U. Teen age menstrual problems - genital tuberculosis a strong possibility. Bombay Hospital Journal Special Issue 1999; 1-5.

3. Dars S, Sayed K, Yousufzai Z. Relationship of menstrual irregularities to BMI and nutritional status in adolescent girls.Pak J Med Sci 2014; 30(1):140-44.

4. Chauhan Madhubala, Kala Jyoti. Relation between dysmenorhea and body mass Index in Adolescents with Rural versus Urban Variation. The Journal of Obstetrics and Gynaecology of India July-August 2012; 64(4): 442-5.

5. Malhotra N, Kumar P, Malhotra J, Malhotra Bora N,Mittal P. Jeffcoate's Principles ofGynaecology.8th ed.Jaypee Brothers Medical Publishers (P) Ltd.;2014.

6. WHO expert consultation. Appropriate Body Mass index for Asian populations and its implications for policy and intervention strategies. The Lancet, 2004; 363: 157-63.
7. Andersch B, Milsom I. An epidemiologic study of young women with dysmenorrhoea. American Journal of Obstetrics and Gynecology. 1982; 144(6): 655-60.

8. Rajsingh V, Mohite, Vaishali R.Mohite. Correlates of menstrual problems among rural college students of Satara district. Al Ameen J Med Sci 2013; 6(3): 213-18.

9. Khodakarami B, Masoumi SZ, Faradmal J, Nazari M, Saadati M, Sharifi F, Shakhbabaei M. The Severity of Dysmenorrhea and its Relationship with Body Mass Index among Female Adolescents in Hamadan, Iran. Journal of Midwifery and Reproductive Health. 2015; 3(4): 444-50.

10. Patil S,Wasnik V,Wadke R.Health Problems amongst Adolescent Girls in Rural Areas of Ratnagiri district of Maharashtra India. Journal of Clinical and Diagnostic Research.2009; (3)1784-90.

11. Abdella NHA, Add-Ethalim EHN, Attia AMF. The Body Mass Index and Menstrual Problem among Adolescent Students. Journal of Nursing and Health Sciences, July-August 2016; 5(4): 13-21.

12. El-Gilany AH, Badawi K, El-Fedawy S. Epidemilogy of dysmenorrhoea among adolescent students in Mansoura, Egypt. East Mediterr Health J. 2005 Jan-Mar; 11 (12):155-63.

13. RupaVani K, Veena K.S, Subitha L, Hemanth Kumar V.R, Bupathy A. Menstrual abnormalities in School going girls-Are they related to Dietary and exercise Pattern? Journal of Clinical and Diagnostic Research 2013;7(11): 2537-40.

14. Hong Ju, Mark Jones, Gita D. Mishra. A UShaped Relationship between Body Mass Index and Dysmenorrhea: A Longitudinal Study. PLoS One. 2015; 10(7): e0134187. Published online 2015 Jul 28 . doi: 10.1371/journal.pone.0134187

15. Margaret A, Dash M. Relationship between BMI (Body Mass Index) and Dysmenorrhoea among adolescents in a College of Nursing at Puducherry, India. Int. Res. J. Medical. Sci., March 2016; 4(3): 4-6. 
16. Lee L K,Chen $P$ C Y,Lee $K$ K, Kaur J. Menstruation among adolescent girls in Malaysia: a cross sectional school survey. Singapore Med J .2006; 47(10): 869.

17. $\mathrm{T}$ Santina, N Wehbe, FZiade.Exploring dysmenorrhoea and menstrual experiences among Lebanese female adolescents. Eastern Mediterranean Health Journal. 2012; 18(8): 857-63.

18. Suresh K. Kumbhar, Mrudula Reddy, Sujana B,Roja Reddy K,Divya Bhargavi K, C.Balkrishna. Prevalence of dysmenorrhea among adolescent girls (14-19 yrs) of Kapada district and its impact on quality of life: a cross sectional study. National Journal of Community Medicine 2011;2(2): 265-8.

\begin{tabular}{|l|l|}
\hline \multicolumn{2}{|c|}{ Access this Article in Online } \\
\hline & Website: \\
\hline & www.ijcrims.com \\
\hline Quick Response Code & Subject: \\
\hline
\end{tabular}

How to cite this article:

Gurdip Kaur, Parmjit Kaur, Himani. (2017). A Study of the relation of BMI with dysmenorrhea in adolescents girls. Int. J. Curr. Res. Med. Sci. 3(8): 65-70.

DOI: http://dx.doi.org/10.22192/ijcrms.2017.03.08.011 